\title{
CDISC ADaM Derivation Type Terminology
}

National Cancer Institute

\section{Source}

National Cancer Institute. CDISC ADaM Derivation Type Terminology. NCI Thesaurus.

Code C81224.

Terminology associated with the Derivation Type codelist of the Clinical Data

Interchange Standards Consortium (CDISC) Analysis Data Model (ADaM). 